\title{
Youth Justice and Education: A Typology of Educational Approaches to the Resocialisation of Young Offenders in Spain
}

\author{
Felipe Morente Mejías ${ }^{1}$, Inmaculada Barroso Benítez ${ }^{1}$, Charlie Davison ${ }^{2,{ }^{*}}$ and \\ Gillian Green² \\ ${ }^{1}$ Ciencias Sociales y Jurídicas, Universidad de Jaén, Paraje Las Lagunillas S/N, 23071 - Jaén, Spain \\ ${ }^{2}$ School of Health \& Human Sciences, University of Essex, Wivenhoe Park, CO4 3SQ, England
}

\begin{abstract}
The Young Offenders Act that entered Spanish law in 2000 represents a significant attempt to place personalised educational programmes for young people with social/criminal problems at the centre of policy and practice. This paper examines the teams and educational programmes designed to manage and implement the goal of 're-socialisation' enshrined in the Act. This paper focuses on an analytical typology of the educational styles used at young offenders institutions in Spain. The analysis highlights the differences between styles in relation to the key underlying objectives of social reorientation and citizen empowerment. The wide range of models experimented with in different Spanish regions has great relevance to youth justice systems in other countries. For example, the typology we put forward has concrete implications for recent developments in England, in the light of moves towards establishing a national network of "Secure Colleges" for convicted young people.
\end{abstract}

Keywords: Young offenders, education, rehabilitation, juvenile delinquency, secure colleges.

\section{INTRODUCTION}

The Young Offenders Act (Ley del Menor 2000) that became law throughout Spain at the start of the new century is a clear and definite attempt to place the punitive structures dealing with youth crime firmly in the context of a welfare-driven approach to children and adolescents at 'social risk'. A key aim of the Act was to ensure a successful education-based rehabilitation intervention in all centres for all cases and facilitate the establishment of level of social stability in the lives of convicted offenders. However, a recent report by the "Defensor del Pueblo" (People's Defence Office - a state funded legal agency whose function blends those of a 'national audit office' for judicial affairs with those of an 'ombudsman') highlights the continuation of a varied approach with mixed results in terms of the sustainable protection and long-term welfare of the vulnerable young people who are cared for in secure accommodation and young offenders institutions:-

"The investigation carried out by the People's Defence Office concludes that the results of the educational protection system are not always deemed satisfactory by the educators themselves. Only in very few cases are they seen as satisfactory by the young people themselves. This is true both during their detention in centres of various kinds and

*Address correspondence to this author at the School of Health \& Human Sciences, University of Essex, Wivenhoe Park, CO4 3SQ, England; Tel: (+44) 1206 899612; Fax: (+44) 1206 873765; E-mail: cdavison@aspects.net also after they have reached 18 years of age. Many are forced to leave the centre where they have been receiving their educational attention even though they have not passed or completed the programmes of therapeutic intervention they have been following"

\section{(Defensor Del Pueblo/People's Defence} Office 2009:404)

These perceived shortcomings in the youth justice system reported by professionals acting on behalf of young offenders have to find their place in a wider public discourse that focuses on the 'social dangerousness' of young people. In Spain, as in other European countries, apparent increases in youth crime and anti-social behaviour contribute to a background "demonisation" of young offenders (Goldson 2000). The combination of official disquiet about the success of education on the one hand and a public mood characterised by anxiety about youth crime on the other has important implications for the development of professional practice. In particular it opens the way for any perceived lack of positive results to be blamed on the faults of particular educational philosophies as well as the content and delivery of specific programmes.

Theoretically, this questioning of what underlies philosophies and styles in offender education is interesting to examine. For example, Savater (2003) emphasises the necessity of presenting the learner with the full "perplexity of the world" so that the assumption of personal responsibility can lead to long- 
term self-sufficiency and the sustainability of good citizenship. But, in Savater's observation, this level of technical educational 'know-how' has yet to be reached in the real world.

The backdrop to Savater's argument is that, in society, there is no agreement on the social causes of unrest and the pervasive civil insecurity that goes with it. Neither is there a generalised acceptance of the nature of the social complexity underlying such problems. This brings about a tendency for the source of insecurity in the wider society to be attributed to the marginality of certain social actors and/or onto the phenomenon of social division itself. Thus the most important theoretical aspect of education for young offenders becomes the need to understand the effects generated by social structures - specifically how "juvenile delinquency" rather than "normality" is produced.

This intellectual framework can best be understood in the light of the identification of "uncertainty" as a central theme in contemporary Western cultural life - a process which sociologists have called the "risk society" (Beck 1992). This notion proposes the idea that risk in contemporary western culture is, unlike the specific and discreet risks of past eras, characterised by its intangibility and omnipresence in any and every field of social reality. Lechner (1990) notes that due to the lack of absolute principles defining certainty, what emerges from contemporary Western culture is a perception of a generalised fear/threat, which in turn lead societies to prioritise the demand for certainty. In terms of modes of response to youth crime and antisocial behaviour, this theoretical perspective provides the foundation for the notion that we can look at educational work with young offenders from a social/collective perspective rather than focusing exclusively on individual responsibility. In other words an outlook that proposes that delinquent behaviour is more rooted in contextual factors than in the attitudinal motivation of any one individual.

This paper therefore addresses the relational fields in which institutional actions take place in the context of contemporary approaches to young offenders' education in Spain. The article then goes on to assess systematically the different methods we observed surrounding the learning and educational processes experienced by those who are identified by the judicial system as being in need of social reorientation. In this work we highlight two related areas. On the one hand we focus on the general socio-cultural context in which youth offending is understood in contemporary Spanish society. On the other we look specifically at the different educational models practised in various reform centres. Our fieldwork has taken place in the context of Spain's Autonomous Communities, which are the governmental units responsible for implementing the general principles and actions laid down in the national Young Offenders Act (Ley del Menor 2000). The striking heterogeneity of the educational styles and practices we describe is at least in part a function of the regional autonomy that characterises Spanish social policy in general. A major aim of this article is to analyse the wide variety of professional practice being implemented in Spain by constructing a typology of educational approaches that can also contribute to an understanding of the field throughout Europe and the wider world.

A brief description of the constitutional situation in Spain is needed to give some context to the striking variety of youth justice practice in the country. Under the post-Franco constitution of 1978, the right to autonomy of the different "communities and nations" which make up Spain is both recognised and guaranteed by the national state. In practice this means that all areas of policy (with the exception of foreign policy and defence) can, in theory, be devolved to the governments of the regional communities (known as "Autonomous Communities"). The communities are free to make their own individual constitutional settlement with the central state - in effect opting in to different levels of autonomy. The famously independence-minded regions of Euskadi (the Basque homeland) and Cataluña have opted for the maximum permitted level of autonomy, while smaller and more traditionally "spanish" regions (such as La Rioja, or the Community of Madrid) have chosen to leave many more areas of policy and administration in the hands of the central state. Other Autonomous Communities sit somewhere on the spectrum between these extremes.

A certain level of national cohesion, even in areas of devolved power, is guaranteed by a set of universal laws (known as "organic laws") that set out the general principles and standards in any given substantive area. These laws have the status of the constitution itself and can only be formulated and changed by the national parliament. The interpretation of the general principles enshrined in organic laws, along with the commissioning and administration of the public services which they imply, are competencies which are carried out by the parliaments and governments of the Autonomous Communities. The world of Youth Justice 
is one such area. The field is governed by the overall principles of the 'Ley del Menor' (the Organic Law of the Child adopted by the national parliament in 2000). Within the confines of that general law, individual Autonomous Communities pass their own local regulations, devise their own systems of punishment and rehabilitation and set up quite different professional and administrative structures to provide and regulate services. This constitutional arrangement makes Spain a fertile territory for comparative research.

Our work is carried out within an intellectual approach to the world of crime that stresses an interest in the social and historical contexts of social action. Such an approach places the cultural and behavioural foundations of youth offending within a wider analysis of the 'social divergence' of young people. The key idea here is that plausible explanations and understandings of different outcomes need to be sited within the different socio-cultural contexts of the interventions that produce them. With this idea in mind, one of our main observations is that contemporary Spanish society is characterised by the huge structural changes that have taken place in the recent past often described as 'in just one generation'.

\section{CHANGES IN SOCIAL STRUCTURE AND THEIR INFLUENCE ON EDUCATIONAL STYLES}

The societal model that was dominant in Franco's Spain between the late 1930's and the mid 1970's was one based on full employment, the traditional nuclear family and a paternalistic welfare structure under the aegis of an overtly powerful and clearly defined autocratic state. This very clear and concrete structure to social, cultural and political life has been superseded over three decades by a socio-economic environment characterised by freer markets, greater competition and a stronger emphasis on individualism (de Miguel 1990). These fundamental changes have appeared as central analytical themes in our biographical approach to youth culture (Morente 1997). Above all, changes to the labour market have come to the fore - specifically the emergence of a wide range of employment patterns characterised by economic diversification, the rise of large scale structural unemployment, a marked volatility in the availability of work and the emergence of women as a key element in the labour force (Ross et al. 2002).

These economic changes have taken place in the context of a dramatic increase in immigration and the rapid development of a new multiculturalism in Spanish society. These demographic developments have brought about a redefinition of social space and new forms of social stratification (de Miguel 1990). On a normative level, concomitant changes in the 'moral order' of Spanish society are also striking. In terms of consumption and the use of time it is often noted that a set of 'old fashioned values' (including frugality, mutual assistance and self-control) have given way to new cultural and behavioural forms characterised by individualism, materialism (in the consumerist sense) and ostentatious signs of status and wealth (Gies 1990, Hooper 1995).

The perception of a weakening (or even a disappearance) of a traditional or long-standing social 'mesh' tends to threaten the ideals and 'metanarratives' of modernity. In the words of Jock Young, everything we say and think about social and cultural change becomes "related to the steep rise in crime and incivility, just as with the debate about rules and models that is currently taking place...... Crime is no longer unusual or abnormal; offences are not marginal or strange but are commonplace in everyday life" (Young 1994).

Young argues that the characteristics of social structures and the ways in which they emerge must be taken into account when analysing a phenomenon in its social context. We have found that this is especially true when analysing the design and implementation of projects aimed at teaching children and young people who are enrolled in reform programs. New values, new codes of understanding, and new expectations allow and require other forms of interaction with people. This is a more horizontal plan of reciprocity, even in the institutional framework in which the established contract base is defined from a position of authority. Under this new context, it should be noted that institutional reform is a social space in its own right, separate from everyday life. Therefore, this cannot be seen as a 'normal' situation in which socially disorientated offenders have the opportunity to redefine their lives. Given the opportunity that detention methods 'offer', it becomes feasible for professionals and educational agencies to propose specific methods involving new ways of dealing with 'discipline' and the promotion of novel forms of interaction between teacher and student, in which trust plays the fundamental role in everyday relations. In this context trust and expressiveness can go hand-in-hand with, and sometimes in place of, institutional discipline. As Savater puts it, it becomes possible to "regain the causes that allow us to truly distinguish between what is right and wrong in education." (Savater 2003) 
Our analysis is also strongly influenced by overall distinctions in the political atmosphere surrounding the concept of youth justice internationally and in particular the tensions between punitive culture and rights identified by Muncie (2008) and 'young offenders' and 'children in need' proposed by Goldson (2000).

\section{METHODOLOGY - OUR RESEARCH INTO EDUCATIONAL INTERVENTIONS WITH YOUNG OFFENDERS}

In recent years there has been a marked increase in research focusing on the social conditions in which adolescence unfolds in Spain, much of which builds on the solid foundations of social analyses of crime in the twentieth century (e.g. Salillas; Bernaldo de Quirós and J.M. Llanas, amongst others). This interest from the academic community has been matched by notable efforts in the world of practice to professionalise the services and programmes which deal with young offenders. These developments have taken place against the backdrop of unparalleled media and public interest in adolescent anti-social behaviour, youth crime and new expressions of social conflict amongst the urban young, such as gang culture (Costa 1996).

With this scientific and professional context in mind, our research into educational interventions with young offenders has aimed to provide an insight into a little researched, but potentially revealing field of study. We have placed a particular emphasis on the educative relationship between teams of teachers and the young people who are enrolled into their programmes, rather than the formal educational 'systems' in which they are situated. Because of our interest in the social processes involved in work with young offenders, we have employed qualitative research techniques. One of our reasons for using this strategy is to complement other recent studies that have offered a broad and comprehensive analysis in statistical terms of the situation surrounding juvenile justice in Spain (Cea d'Ancona, 1992; Perez Jimenez 2005).

Our field research has been based on the principle that the best environment for ascertaining the views and perceptions of those involved in interventions is the social space of the detention centres themselves. Here the effects of educational systems are directly manifested, allowing the researcher to explore the consequences of face-to-face relations between teacher and offender. In these settings we have tried to understand the impact of educational practices as an expression of discourse of the intended objectives (the social rehabilitation and emancipation of children). Above all we have tried to analyse the models of relationships between the professional teams and their young 'clients', and their engagement with the overall culture of compensatory justice and personal reform in which they find themselves.

Our fieldwork consisted of observations and interviews with professionals and with young offenders in 13 centres distributed in 5 Autonomous Communities in Spain. The centres were "purposively sampled", that is to say that they were chosen to reflect the differences between on the one hand institutions running relatively 'closed' regimes in which offenders are kept apart from the rest of society 'behind locked doors' with highly controlled and formalised contact at prescribed visiting times and on the other relatively 'open' regimes. In the second type there is more permeability between the unit and the wider society with regular and flexible visiting by friends and family to the institution and vice-versa.

The five Autonomous Communities were Andalucía, Cataluña, Madrid, Extremadura, and La Rioja. These Autonomous Communities were purposively selected to reflect the different left/right political complexions of regional administrations, which can be striking under the Spanish system of devolution to regional level. In each community, examples of both different kinds of institution were visited. Fieldwork visits consisted of periods of unstructured observation, punctuated by formal, private interviews with staff and young offenders (it is the interviews and discussions with the professionals which are reported here). The observational work took place in a variety of settings including classrooms, workshops, gardens, common rooms, group discussion sessions involving inmates and staff, bedrooms and also "tours" of institutions (the guides on some occasions being the young inmates themselves and in some cases staff). Informal observations lasted between 20 minutes and two hours and were not characterised by recording or contemporaneous note taking.

The 22 formal interviews with professionals were digitally recorded. They followed a flexible, unstructured style in which the informant was given freedom to tell their own story as a narrative and respond to generalised and open-ended prompts and questions about their thoughts on youth offending in general and the educational programmes in particular. No formal topic guide was followed, with every attempt being made to give control over the "agenda" of the 
conversation to the participant. Field notes from the observational visits and informal discussions were made in private from memory later in the day in question or on the following day. Tables 1 and 2 show the characteristics of the institutions visited (where unstructured observations, informal discussions and formal interviews took place) and the make up of the formal interview sample. Further details of the fieldwork with precise geographical locations are described in Morente (2009).

The fieldwork material was analysed using simple thematic analysis. Written notes and memories from observations were reflected on by members of the research team and discussed in group meetings. The typology we advance in this paper grew out of these analytical discussions. The interview recordings were transcribed and the texts were entered into the Max QDA qualitative data software package. The thematic structure which was developed during the group discussions was used to make the coding system in Max QDA and it is from this level of analysis that the typology we advance in this paper emerged.

Concretely, our analysis started from the observation that the Spanish youth justice/personal reform system is operating in the context of the same basic dichotomy that is found in other parts of the world and on which most contemporary ideological differences on the subject of juvenile justice are ultimately based. One position making up the dichotomy is the notion that punitive action is a necessary, unavoidable and indeed desirable consequence of a judicial process that finds an individual guilty and bestows on them the "offender" label/status. The second position holds that the "offence" should only be understood as a social production - the result of socio-economic conflict and cultural/family dislocation. These 'collective' problems require the development of an appreciative dialogue

Table 1: Characteristics of the Instituions Visited for Observations, Informal Discussions \& Formal Interviews

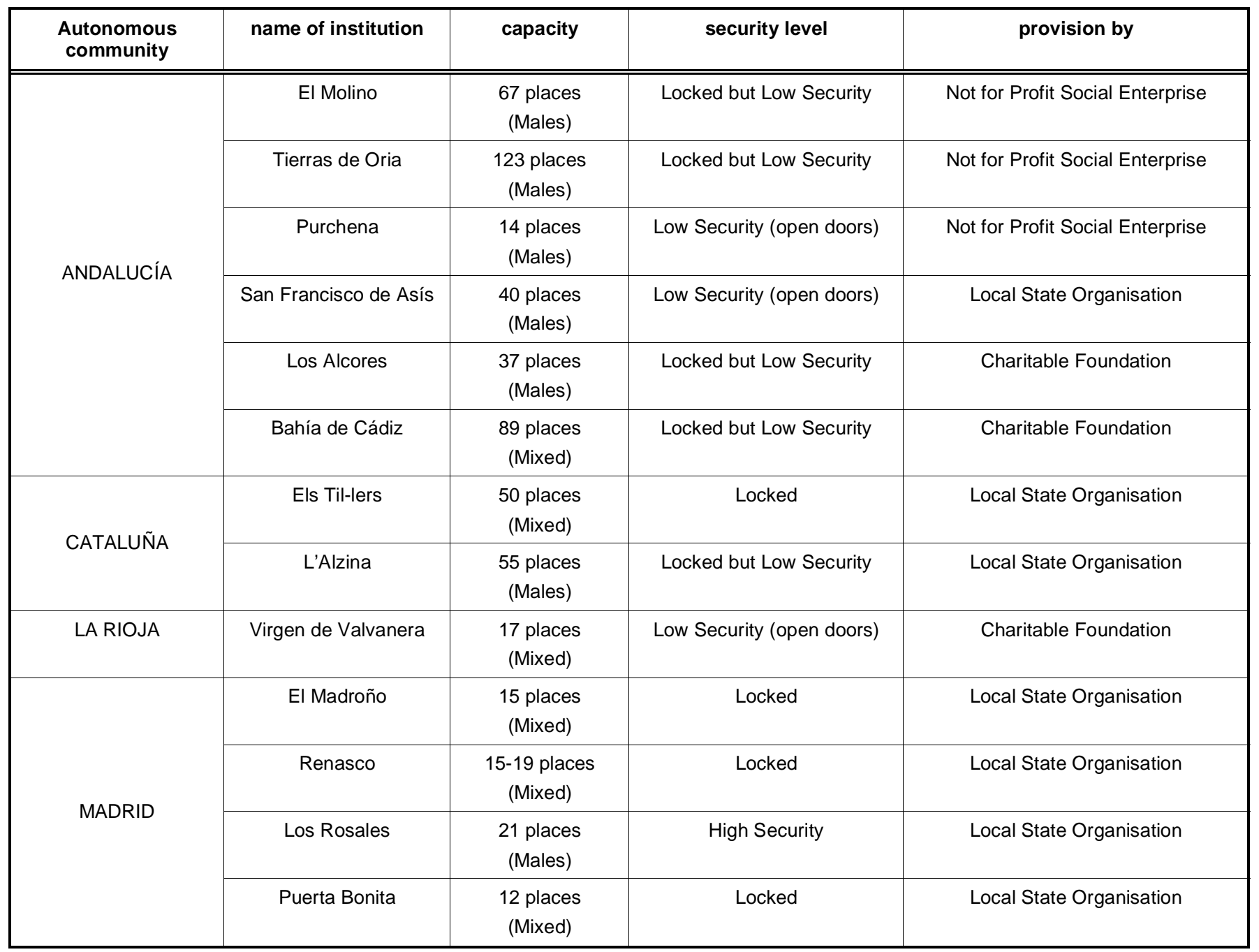


Table 2: Characteristics of the Professionals Formally Interviewed

\begin{tabular}{|c|c|c|}
\hline POSITION / ROLE & AGE / GENDER & AUTONOMOUS COMMUNITY \\
\hline Regional Government Cabinet Member & Not recorded / F & Andalucía \\
\hline Head of Regional Youth Justice Service & Not recorded / M & Andalucía \\
\hline Judge specializing in Youth Justice & Not recorded / M & Andalucía \\
\hline Director of Youth Justice Institutions & Not recorded / M & La Rioja \\
\hline Head of Regional Youth Justice Service & Not recorded / M & Cataluña \\
\hline Head of Regional Youth Justice Service & Not recorded / M & La Rioja \\
\hline Director of Youth Justice Institutions & Not recorded / F & Madrid \\
\hline Director of Young Offender Institution & Not recorded / M & Andalucía \\
\hline Social Worker & Not recorded / M & La Rioja \\
\hline Director of Young Offender Institution & Not recorded / M & Cataluña \\
\hline Deputy Director of Young Offender Institution & Not recorded / F & Andalucía \\
\hline Educator & Not recorded / M & Madrid \\
\hline Team Leader & Not recorded / M & Andalucía \\
\hline Director of Young Offender Institution & Not recorded / F & Andalucía \\
\hline Director of Young Offender Institution & Not recorded / M & La Rioja \\
\hline Director of Young Offender Institution & Not recorded / M & La Rioja \\
\hline Director of Young Offender Institution & Not recorded / F & Cataluña \\
\hline Director of Young Offender Institution & Not recorded / M & Andalucía \\
\hline Director of Young Offender Institution & Not recorded / M & Andalucía \\
\hline Educator & Not recorded / M & Extremadura \\
\hline Director of Young Offender Institution & Not recorded / M & Andalucía \\
\hline Social Worker & Not recorded / M & La Rioja \\
\hline
\end{tabular}

with authority during which the offender becomes aware of their structural and personal contexts. These points of view are based on quite different ontological notions of crime and are succinctly summarised by Goldson (2000) as the dichotomy between "children in need" and "young offenders".

Our 'microscopic' focus on the everyday processes involved in real life re-education programmes aims not only to throw light on these attempts at rehabilitation themselves but also on the structure and function of Spanish and other juvenile justice systems. Our typology of educational approaches has emerged from the fieldwork data, through the processes of identifying common themes and refining them through group discussion and debate. In this sense, the ideas we advance in this paper are the results of a relatively 'classical' qualitative research approach

\section{Educational Approaches and Educational Programmes in the Spanish Youth Justice System: A Comprehensive Typology}

There have been some previous studies of socialeducational reform programmes in Spain and our proposed typology is an attempt to build on their insights. Julio Carabaña (2005:19-23) discusses an ideological polarisation on the role of authority and force in schools. Within this structure, three interests or objectives can be distinguished: behavioural, moral educational, and active educational. We should note here that these are ideological distinctions and do not directly map onto the reality of educational practices in real-life institutions. In actual professional practice settings, it is possible to observe a combination and interplay of more than one of the three ideological tendencies, 'blended' in various ways. We refer to these elements of practice as "approaches" and label them: the behavioural approach, the moral education approach, and the active education approach (based on democratic authority).

The following table presents a summary of the basic characteristics of each approach: the intended principles that each represent to the programmes in which they are being used; the influence each approach has on the role adopted by the educator in a real practice situation; the ideologically defined nature (which we have called "character") that each approach projects onto the young client; and finally, the underlying strategic ideology on which the offender profile is predicated. 
Table 3: Typology of Ideological Approaches Informing Practice in Social-Educational Programmes for Young Offenders in Spain

\begin{tabular}{|c|c|c|c|c|c|}
\hline 'APPROACH' & Basic Characteristics & $\begin{array}{c}\text { Intended } \\
\text { Principles }\end{array}$ & $\begin{array}{c}\text { Role of the } \\
\text { Educator }\end{array}$ & $\begin{array}{c}\text { Character of the } \\
\text { Young Offender }\end{array}$ & $\begin{array}{c}\text { Ideological } \\
\text { /Strategic } \\
\text { Position }\end{array}$ \\
\hline \hline $\begin{array}{c}\text { TYPE 1 } \\
\text { Behavioural }\end{array}$ & $\begin{array}{c}\text { Coercion, discipline, } \\
\text { behavioural control, } \\
\text { behavioural stimulation }\end{array}$ & $\begin{array}{c}\text { Rehabilitation: } \\
\text { changing the } \\
\text { individual }\end{array}$ & $\begin{array}{c}\text { Coercive. With } \\
\text { power to } \\
\text { reward/punish }\end{array}$ & $\begin{array}{c}\text { A deviant individual, } \\
\text { unaware of social } \\
\text { rules }\end{array}$ & $\begin{array}{c}\text { Neo-correctional' } \\
- \text { neutralisation of } \\
\text { risk }\end{array}$ \\
\hline TYPE 2 & $\begin{array}{c}\text { Search for self-control and } \\
\text { the use of work for pleasure } \\
\text { and interest }\end{array}$ & $\begin{array}{c}\text { Integration: } \\
\text { changing attitudes }\end{array}$ & $\begin{array}{c}\text { Identification. } \\
\text { Transmission of } \\
\text { knowledge }\end{array}$ & An incomplete adult & $\begin{array}{c}\text { Social assistance } \\
\text { and moral } \\
\text { reintegration }\end{array}$ \\
\hline TYPE 3 & $\begin{array}{c}\text { Individual freedom and } \\
\text { development. The right to } \\
\text { expression and } \\
\text { participation. }\end{array}$ & $\begin{array}{c}\text { Democratic } \\
\text { Socialisation: } \\
\text { inserting the } \\
\text { individual into a fair } \\
\text { community }\end{array}$ & $\begin{array}{c}\text { Influence through } \\
\text { dialogue } \\
\text { ("maieutic") }\end{array}$ & $\begin{array}{c}\text { A subject with the } \\
\text { right to be treated in } \\
\text { the same way as } \\
\text { any citizen }\end{array}$ & $\begin{array}{c}\text { Participatory } \\
\text { democracy }\end{array}$ \\
\hline
\end{tabular}

Table 3 defines the analytical and conceptual framework of the three educational models found in professional practice. In the following three sections of this paper we present an analytical discussion of each approach based on qualitative analysis of the material collected during the interviews and observations that made up our field research. The analysis of each approach is illustrated with verbatim quotes from the educators working on the various programmes visited. They embody the distinctive features of educational styles practised in these institutions. The statements are all taken from interviews with teachers and representatives of the management of educational teams responsible for the programmes being run at the centres.

\section{Type 1. The Behavioural Approach}

This approach is defined by an interventionist philosophy expressed through the practice of monitoring behaviour through reward and punishment. The basic model is one of behavioural stimulation. The appearance of this approach in young offenders custodial institutions and in community programmes generally involves the use of discipline to correct undesirable or unusual behaviour, as well as to prevent abusive behaviour. The concept of discipline that is identifiable in this approach corresponds closely to the analysis found in Foucault (1975) which pictures a mechanism of power allowing for the control of social bodies by bringing into play their own social atoms, i.e. individuals. The educational practices associated with this approach are centred on a set of techniques representing power, control and discipline in this Foucauldian sense: - how to watch someone, how to control their behaviour, how to develop their behavioural skills, how to enhance their performance, how to multiply their capabilities, how to put them in the most useful place, and how to help them fill their time and adjust. The exercise of discipline in the behavioural approach that we observed and identified in the interviews we carried out also emphasises the necessity and centrality of an over-arching set of rules which need to be systematically adhered to: - legal structures, legal principles and the regulation of administrative violations.

This process of 'disciplining through structures' requires that young clients be singled out from the overall multiplicity of offenders in the institution and treated as individuals. In this approach minors must go through a learning process and/or a detention regime, through which they become skilled in something and therefore more valued. The greater the need is to alter behaviour the more effective the teaching techniques need to be, more dedication and time must be devoted to the learning process. In this sense the behavioural approach stresses a step-by-step approach to the progress of each young person and emphasises the need for a practical programme for each individual.

Type 1. Behavioural Approach. 'What's our model? Our model is the practice (emphasised) of any model, I mean we might use or not use any model or philosophical theory, right? I don't like the psychology professors or the educational .. that come up with ten thousand theories and discuss them in ten thousand conferences. I don't see them using their models to help children, you get me? They just talk and talk about 'the child' but does 'the child' get a say? Does the family get a say? Do they even interact with children at 


\section{all?.' (P9 - Director of a High Security Unit, Andalucía)}

In terms of the conceptualisation of authority and the role of the educator, the commonly accepted ideal of professional practice is work that promotes compliance and obedience. However, analysis of the interviews relating to this model suggests two different types of power relationship in the construction of the understanding authority, one focused on punishment and the other on reward.

"Coercive power" is based on the teacher's perception of the youth as a mediator of punishment. Their power depends on the level of punishment and the subjective probability (perceived by the adolescent) of avoiding punishment by behaving in the required way. By this we mean that the probability of being punished is clearly lower when an adolescent complies with certain rules. This implies that changes produced by coercive power are more dependent on the presence of an educator than changes produced in any other way. In this sense, the behavioural approach involves the recognition that changes brought about in the observable behaviour of the client need to be understood in the context of a less concrete though more complete agenda of personal reform. Practitioners adopting the behavioural approach also recognise that if the educator exerts their influence in a coercive manner this can reduce the trust young people have towards them and even lead to a tendency to distance themselves from programmes.

"Reward power" is based on the idea of the teacher as a mediator of small benefits. Their power depends on the level of reward on offer and the subjective probability (perceived by the adolescent) of being rewarded if they change. The young client is also perceived as having to face the possibility of not being rewarded if they do not change. The effectiveness of the role of educator depends on the physical presence of the facilitator (the teacher) as the exercise of power is limited to behaviour that is seen and can therefore be rewarded. The use of reward power is seen on the one hand as increasing the potential of the educator to identify and change significant behaviours, but on the other recognises that if the educator promises prizes which later cannot be provided (for example because of a later repeat of bad behaviour) this diminishes the legitimacy of the practice.

With regards to the ideals of rehabilitation, what most stands out is what we could call "rationality" or purpose. This practicality is in many ways the hallmark of the behavioural approach. The ideology this approach employs places an emphasis on 're-training' and the provision of basic skills because it is axiomatic to the approach that a minor who has committed a crime is someone who has not learned the necessary social rules. However, when results do not coincide with the objectives, different possibilities arise. Either the institution needs to be reformed or the defects (or even 'failure') of the programme need to be construed as meaningful and in some sense useful. Through this practical reasoning, centres that have not achieved the amendment of young offenders can at least be seen as having served as a mechanism of social separation and custody.

In terms of Foucauldian analysis, it could therefore be argued that disciplinary rehabilitation programs characterised by the behavioural approach do not necessarily need to express a dominant ideology. Legal structures that regulate criminal convictions do not conform to theories of welfare as much as they do to ideas of incarceration and punishment. The possibilities of rehabilitation in the criminal justice system are routinely subordinated to other law enforcement targets, particularly the need for retribution, the removal of offenders from normal society and the management of the risk of crime.

Type 1. Behavioural Approach "We
understand security in a different way,
here we understand security as a person...
children (allow me to call them children, or
juveniles, or youths) who come and
complete a measure that has been issued
by a court, a young offenders judge. They
must understand this measure has to be
fulfilled, that they have to comply with it,
otherwise they'll run off tomorrow. So
many schemes are abandoned through
the idea of "I'm getting out of here, what
can we break up, where shall we go".
They have to complete it and know that
they're going to be here, in order for us to
achieve our educational and therapeutic
objectives." (P9 - Director of a High
Security Unit, Andalucia)

\section{Type 2. The Moral Education Approach}

The moral education approach is characterised by one essential criterion, the charisma of the teacher as a mechanism for inspiring change in the young client. 
Above all it looks to instil a level of self-control and selfknowledge based on two pedagogical principles. On the one hand an understanding that the ability to recognise pleasure and self-gratification represents a didactic opportunity and on the other an understanding that pleasure and self-gratification are at least amoral, if not immoral, and that the client needs to develop a sense of duty, the ability to overcome desire and the wherewithal to sacrifice self-interest.

In terms of the theory and ideology underlying moral education, practice is often driven by the idea that a more contemporary risk control approach can coexist with older punitive systems of training and punishment. Practitioners recognise that there have been changes in the official response to crime, but that the greatest change to have occurred in recent decades is in the place that crime has in everyday discourse and in the imaginary socio-cultural environment. The approach needs to appeal to the moral dimension of the individual because it recognises that the lack of integration between the educational system and the labour market means that there can never be a guarantee of permanent gainful work for all citizens. Indeed it recognises that the overall socio-economic structures are more likely to produce an underclass in society - a population that is excluded from social and economic life. Because of this it becomes vital to intervene at the individual moral level, in order to equip the young client with the personal skills and mind-set that may allow them to both achieve and sustain a stable position in an uncertain world.

Type 2. Moral Education Approach. 'It's not my ultimate goal to rehabilitate youths back into the public sphere. It would be useless to prepare them to sign a contract and ignore the reinstatement of social skills. My ultimate goal is that the kids leave here with a job which they intend to respect and know how to keep. In other words, I want them to be able to respect their peers, to leave here with values of honesty and truthfulness, so that they become a citizen ...' (P11- Director of a Locked but Low Security Unit - in Spanish "semi-abierto" - Andalucía)

This pattern of rehabilitation has a triple purpose: helping the offender become a person who has the intention and capacity to respect law and order, giving them the ability to respond to their own needs; developing the young offenders attitude towards respecting themselves as an individual and implanting a level of social responsibility with regard to their family, neighbours and society in general. This is centred on the careful modification of human behaviour and the moral education approach welcomes with open arms any therapeutic technique linked to an evidencebase in the academic behavioural sciences. Techniques discussed by our informants in this light included 'identifying issues', 'planning intervention to change outcomes' and 'reacting to developments'.

The existence of the moral education suggests that there has been an epistemological change in the criminal justice world, whereby going to see a psychologist, psychiatrist, or social worker is a routine judicial act. In this sense, a young offender is seen as an incomplete adult, or as a weak individual who should receive all possible assistance during the process of rehabilitation and social integration. An extension of the approach opens the way to psychiatric approaches based on a discourse in which the illegal behaviour of an offender is recast as a product of individual pathology and personality disorders.

Type 2. Moral Education Approach. 'The model which we practice is the cognitive behavioural model, where depending on the individual minor, one aspect may be more important than another... behaviour being the most important thing, yeah? The child has to know about their own history just as much as they need to accept the consequences of it: they don't know how to anticipate these consequences, they don't know when their behaviour has been positive or negative... So, what we're trying to do is to help them value the consequences of positive behaviour and to realise the effects of negative behaviour.'

(P8 - Director of a Locked but Low Security Unit - in Spanish "semi-abierto" La Rioja)

The main implications that the moral education approach has for the practitioner as a figure of authority are that the charismatic educator should be able to draw upon two sources of power:

'Referent power' is based on the child's identification with the teacher. The greater the teacher's charisma and attraction, the greater the power they have will be. Under the influence produced 
by referent power, the young client ideally becomes independent of the educator and takes control of changes in their own behaviour. On the negative side, this independence has the potential to bring about a range of undesirable behaviours, as well as desirable ones.

'Expert power' is based on the young client's perception of the teacher as the possessor of special knowledge in a particular subject. The expert power of a person usually has a very limited range, limited to specific areas, as it is difficult for any one teacher to be considered 'expert' in a wide range of knowledge or practice. Potentially, therefore, if a teacher attempts to exert such power beyond the field in which they are considered expert, the client's confidence in them may decrease. As with referent power above, the change produced in the client does not necessarily depend on the teachers physical presence and independence can ideally be achieved.

Type 2. Moral Education Approach. 'An ideal scenario would be a micro-society, just like out in the real world, that'd be ideal. The kid has to be autonomous, be responsible for his actions, with supervision of course. As for the professionals, we have to provide guidance, give them the social tools that they can then go and use, we can't just give these children a fish, (as we always say) we have to give them a rod and teach them how to fish. (P3 Director of a Locked Unit, Cataluña)

The epistemological change noted above also brings about a transformation in the overall strategy of the criminal justice system. The deprivation of liberty does not necessarily indicate a simple payback for a crime, but rather an opportunity for treatment, education, and therapeutic work. In the moral education approach, custodial and community programs do not so much demand that offenders change their nature, as ask that they acquire the ability to maintain the minimum demands of a normal life. Once this requirement has been fulfilled, the client is essentially 'owed' help and assistance - their participation in technical training, education and skills programmes is an acquired rather than a given right.

\section{Type 3. The Active Education Approach}

The third approach in our typology represents a different articulation of the relationship between punishment and discipline. The 'active education' approach has at its heart an attempt to establish a democratic relationship between the educator and the young client. The aim is to achieve this through the practice of 'socratic maieutics' - a process by which an open dialogue is established between the practitioner and their young client with the overall aim of building freedom and autonomy in the client/pupil (Ahbel-Rappe \& Kamtekar 2006).

The idea of 'mentoring' in the treatment of young offenders (Newburn and Shiner 2006) is closely related to this approach. The underlying philosophy is encapsulated by Liebel's observation that approaches to criminal justice that rely on restorative policies of citizenship status require "subject-orientated" practices (Liebel 2007). This means, that even in teenagers one can see a responsible subject with the right to expression, so that in cases of conflict or disagreement they can recognise that allowing face to face negotiations is by far the best practice.

Type 3. Active Education Approach.
'Any intervention with a minor involves the
minor themselves, in other words, they're
not guinea pigs here, they're human
beings who we completely respect. We
want to change them but through their
own involvement. (P13- Educator, Locked
but Low Security Unit - in Spanish "semi-
abierto" - Extremadura)

An underlying principle of this approach is that it is not enough if rehabilitation and reintegration systems simply end up with a youth getting a job. Nor is it sufficient to 'simply' get a psychologist to change their personality and attitude. The nature of the client's predicament is not seen as a consequence of problems in the young person's nature, experience or environment, but rather the product of a lack of communication between the individual and the society around them. The basic tool of the approach is consequently dialogue and for this it is necessary to establish a level of security and trust both in the centre as an institution and in the people who live and work in it (both inmates and staff as a community). The first objective of the educational practitioner is, therefore, to develop a sincere and emotional dialogue, through which minors become accepted and valued members of the community represented by the institution. The key idea is that through this they gain confidence in themselves and others. Although it may be tempting to see this democratic approach as being 'soft' in terms of 
regulation ad discipline, this tends not to be the case in our observations. Centres and their practitioners recognise that there remains a risk that abusive situations can often reoccur in the lives of the clients and that undesirable behaviour is often still a possibility. Because of this, programmes using the active education approach normally display the full range of surveillance and basic security procedures found in other Spanish young offender's custodial institutions, although as we note below, the approach requires a close relationship with 'society at large'.

The basic feature of this approach is that it places great emphasis on freedom and the development of individuality. It attempts to avoid the risk of depersonalisation and the loss of initiative that occur as a result of excessive control, because the practitioners feel that, ultimately, the centres are there for the benefit of the young people themselves. All of this requires that the young people have their own time and their own space from which to decide for themselves the structure of the activities carried out. In this we find a second characteristic: the right to self-expression and to full participation in everyday 'centre' life. This must also take account of the young person's perspective by teaching them the skills they need to participate in and integrate into a democratic society - including the skills to understand and respect certain limits. Thus, adults have to behave according to the same values they seek to teach, between themselves and with minors, by renouncing the use of any conduct that may involve violence or abuse.

\section{Type 3. Active Education Approach. "The immaturity that the vast majority of these kids have, and the deterioration of it, makes it difficult to involve them in their own process at this level... [But] when we see that it's possible to work with them, then yes I offer them the opportunity to become the one in the driving seat of their life, to develop their own path." (P13- Educator, Locked but Low Security Unit - in Spanish "semi-abierto" - Extremadura)}

Democratic socialisation is the sought after ideal of this model, and this means the insertion of an individual into a fair and just community that they can see is contributing to their progress in various different ways. Firstly, a relationship between the young people and their families is actively promoted, so as to ensure their safety and to help with their reintegration into a family context. Secondly, integration into the community becomes a concrete objective, including the organisation of environments and activities that foster the most normalised life possible. This is a principle that affects the physical environment of the centres, the outlines of activities and daily routines, the educational opportunities on offer, the leisure activities, personal consumption; and, above all, the opening of these centres to the outside world. Centres concentrate on focussing social and cultural activities outwards, towards the environment from which young offenders are often segregated. This reflects an underlying philosophy that sees crime as a socially produced phenomenon and that consequently sees the rehabilitation of offenders as a process that requires wide social participation.

Type 3. Active Education Approach. 'I'm convinced that, the serving of the sentence aside, the youth's immaturity means that he/she's not the one who should take all the blame. We must convince the offending boy or girl that whilst they are the protagonist of their past they are by no means the sole culprit.' (P13- Educator, Locked but Low Security Unit - in Spanish "semi-abierto" Extremadura)

The ultimate objective of the active education approach is to achieve 'normal life' for the clients Because of this, programmes are open to both sexes and all conditions, friends are allowed to come and go, and family visits can take place more or less whenever the young person and their family want. As far as possible, there is also a normal social life within the institution itself. In summary, this approach aims to recreate the same context in which the rest of the population live. These new institutions differ in various ways from traditional ones:

$>\quad$ They have a tendency to reduce the number of members that they have, and to organise small, stable and heterogeneous groups. In each group, some children would live together continuously, usually they are of differing ages and sexes, and all interact very closely with several teachers.

A link with the young person's family is maintained wherever possible, through regular visits from the parents and close contact between siblings who are often encouraged to integrate and interact with the whole group. 
Integration into the community is fundamental. This is achieved through its proximity to urban centres, the enrolment of children into standard state schools, leisure activities outside the residence and visits to family in the community.

$>\quad$ The physical characteristics of the context are changed, children are distributed into spaces that are made for them to feel at home, with rich and varied educational stimulation appropriate to age (decoration, furniture, etc.).

One of the main implications for the practitioner in the active education approach is the importance of maintaining their legitimate authority in the context of ceding as much power over day-to-day affairs as possible to their young clients. Authority must be based in the perception of the youths that the teacher has the right to influence them. This implies an acceptance of a particular code or set of rules, which state that the teacher has a right to influence children and that they have a duty to accept that influence. Abuses of power by educators diminish their ability to provide positive influences, for example by trying to change the behaviour of someone they are not granted the right to influence, or by using unacceptable punishment techniques. For those professionals whose work is strongly characterised by the active education approach, the personal demands made on the educator and the commitment to walking a difficult 'tightrope' between freedom and discipline which the style demands are often seen as crucial elements to the success of their work. As with the Moral Education approach (Type 2) discussed previously, the quality of 'charisma' is seen as very important here. But over and above this, in the case of the Active Education approach, the educator is required to, at least sometime, eschew professional detachment and include a high level of personal involvement in their practice.

Type 3. Active Education Approach. "I don't want to be Messianic, far from it, but perhaps we're missing some proper educational professionals, who work with marginalised people and have a little bit more personal involvement... With more time, more reflection, more involvement, more studying, and more learning, we must move forward." (P13- Educator, Locked but Low Security Unit - in Spanish "semi-abierto" - Extremadura)
To inculcate a sense of responsibility and solidarity, active education programmes try to create situations in which young people and adolescents directly experience moral realities and have to discover social rules for themselves. The young people themselves develop these social rules which they must entirely or partly regulate, choosing their own 'government' in the form of a committee to be in charge of implementing them. They form their own 'judiciary' and from this experience learn obedience as a norm, along with group support and individual responsibility. To summarise, the active education approach revolves around the following practices:

$>$ Rules of behaviour are the result of group processes. Conflicts, both among inmates themselves and between inmates and professionals, are treated as issues of group fairness/justice between individuals with equal rights.

$>\quad$ The development of responsibility is at the heart of practice. It is important that the assembly or the group has real authority over many aspects of daily life in the centre. Such activities do have their limits and these are clearly stated, but in general the group is given as much responsibility as possible. The idea is encouraged that if a rule designed by the group is broken it should be conceptualised as a failure of the group as a whole, rather than the individual alone. In this context, adherence to rules is defended and encouraged as being in the interest of the group as a whole.

In order to encourage collective responsibility and create trust, it is necessary to create a feeling of collective responsibility, whereby individuals are responsible for the wellbeing of the entire group. In addition, the group is responsible for the wellbeing of the individual, to provide them with support and constructive criticism when necessary. The group must recognise when it has failed an individual.

$>$ Developing the concept of authority as a capacity to mediate in and resolve conflicts fairly. Through this model of intervention a concept of authority is developed based on the ability to resolve conflicts. By acting as mediators in the resolution of conflict, the workers develop a constructive authority and the way in which they make decisions becomes respected. 
By applying the above practices to the working of the institution, the active education approach attempts to ensure that the concept of community is developed and the moral atmosphere of the group progresses towards a higher level of democracy and maturity.

\section{A BRIEF CRITICAL COMMENTARY ON THE THREE MODELS}

Our research work has been exploratory and has had as its goal the identification and detailed description of professional practice and the how this is influenced and at least partially shaped by a political/administrative context. The analysis presented here does not attempt to include an evaluation of the 'success' of different approaches and institutions or the measurement or assessment of outcome. We are not therefore in a position to assess the "pros and cons" of different educational styles in terms of their efficacy even if a scientific or objective methodology and range of agreed outcome measures were available (which, of course, they are not). It is possible, however, to put forward a brief critique of the models in terms of their relationship with two key concepts.

One of these conceptual areas is the idea of 'rights'. In this context, the behavioural approach is rather different to the other two. Rather than place the rights of the young person at the heart of practice, the behavioural approach implies a stronger commitment to the rights of the 'outside', 'law-abiding' community to see justice being done and to be protected from future deviant behaviour. There is a strong sense here that, by offending, the young person has forfeited (or at least suspended) a large slice of their right to autonomy and their right to develop their own understanding of rehabilitation. The behavioural approach, in this sense, is the most prescriptive and, indeed, coercive. Arguably, it is not so much based on the idea that a 'good' young person exists inside the offender and the professional challenge is to reveal or discover that person. Rather it is based on the notion that the offender has been identified (correctly) as 'bad' and the professional challenge is to protect the wider society by transforming the person from the outside, thus making them 'good'. The other two educational styles in our typology tend to emphasise the personal potential that exists already within the young offender - a potential that can only be discovered and liberated by the offender themselves, if treated in a way which not only guarantees their individual rights, but sees those rights as a crucial ingredient in successful practice.
The second key conceptual area that is worth drawing attention to is the notion of 'responsibility' and the locus of control over the production of deviant and criminal behaviour. In this context it could be argued that the main cleavage between the three elements of our typology lies between the third approach (Active Education) and the other two. The Active Education approach carries within it the strong implication that the commission of a crime by a young person is, at least to some extent, the product of a complex set of processes. Crucially, these processes include both overall societal conditions (e.g. poverty and sociocultural marginalisation) and the victimhood of the offender themselves (e.g. their exposure to drugs and alcohol, disrupted or abusive childhoods). The Active Education approach, therefore, emphasises both the acceptance by the young offender that they need to take responsibility for personal change and the recognition that this can only happen if and when their equal position in a democratic society is understood and guaranteed. Both 'partners' in the production of deviant behaviour (the offender and the wider society) are, because of their shared responsibility, in need of change and redemption. The other two approaches, on the other hand, put a much lighter emphasis on (or indeed reject) the idea of a shared responsibility for deviant behaviour and place a much stronger focus on a lack or absence within the young person themselves. The Behavioural approach aims to fill this gap by training and conditioning in a relatively authoritarian atmosphere. The Moral Education approach attempts to bring about a similar outcome by emphasising selfdiscovery and autonomous learning.

\section{THE POTENTIAL INTERNATIONAL RELEVANCE OF THE TYPOLOGY}

The typology of educational approaches we have put forward following our work in different regions of Spain is relevant to other international settings. It is now commonplace throughout Europe and the wider world for the provision of educational services in youth justice settings to be in the hands of a range of state, private and third sector organisations. These different organisations often have their own cultural histories and ideological outlooks and, as we have described, these will permeate the day-to-day detail of how practice is carried out.

The structure of government and administration in Spain, and particularly the responsibility of Autonomous Communities to implement the national Young Offenders Act in their own way, has encouraged 
the development of radically different approaches in social-educational programmes. This variety is also found in other countries and, although social emancipation and self-responsibility almost always appear as the final objectives pursued by all educational programs, the Spanish work shows that a striking variation in ideological inspiration and in the details of professional practice is perfectly possible within the same jurisdiction. A relatively 'abstract' or 'theoretical' understanding of ideological and professional variation becomes, therefore, a crucial tool for politicians, civil servants and commissioners. Our typology is a version of such a tool and this is our intended contribution.

To illustrate the potential use of the typology, we can take as an example the current intense debate and activity surrounding the proposed development of "Secure Colleges" for youth offenders in England (Ministry of Justice 2013, Centre for Social Justice 2013, O'Donoghue 2013, Local Government Association 2013). Under these proposals, the educational dimension of youth justice in England is to be redesigned and based around a programme of "Secure Colleges". The proposed institutions will be, simultaneously, schools and places of incarceration. Because of this dual role, the proposals involve a radical change in the institutional landscape. The new Secure Colleges will be like secondary schools in the sense that they will operate in the context of national norms and standards, such as adherence to the framework of the National Curriculum and developing the abilities of students to sit and pass the ordinary range of exams and qualifications. The new institutions will, on the other hand, be like prisons, in the sense that they will be the setting for young people to serve custodial sentences and will be characterised by secure perimeters and locked doors to prevent free entry and exit.

In terms of the development of professional practice in youth justice work, the proposals for Secure Colleges represent a considerable challenge for educators. More than ever before, the relationship between punishment (by the deprivation of liberty) and rehabilitation (by the delivery of education) will be thrown into stark relief. If the place of education is also the place of incarceration, the hitherto distinct roles of educator and custodian become blurred or even merged. It thus becomes more important than ever for individual practitioners (and, of course, their professional associations) to develop clarity of purpose and outlook and to be confident of their professional boundaries.
Additionally, the UK Government's proposals for Secure Colleges in England overtly aim to develop the role of independent, non-state providers of the service (Ministry of Justice 2013). This would make the commissioning and provision of the new institutions very similar to the way that youth justice services are organised in Spain - by a mixed set of private companies, not-for-profit independent organisations and pre-existing private schools. Each of these would, as we have seen from the Spanish experience, tend to have their own particular ideological outlook both in terms of the balance between punishment and rehabilitation and the variation in emphasis between individual responsibility and social explanations of deviancy. In this context, an understanding based on our proposed typology has the potential to clarify and inform the work of public service commissioners, professionals involved in youth justice educational work and the provider organisations themselves.

\section{CONCLUSIONS}

The proposition that adolescent offenders need to develop strong social skills, in particular by belonging to a group that provides relationships, training, information and purpose is shared. Without this, all of the educators and managers we have observed and interviewed agree, young people in trouble with the law will have serious difficulties integrating into society as a full citizen. We feel that our analysis of the different educational styles that can contribute to the development of skills and a sense of belonging may be particularly relevant for systems characterised by high levels of custodial sentences for young offenders.

Our research shows, however, that in the building of a circle of "significant others" who have the central task of providing vital, relevant and meaningful content to programmes, there is a strong divergence in the philosophical and ideological foundations of professional practice. Moreover, this divergence leads directly to a range of very different lived experiences from the point of view of the young clients. In our analytical typology, we have outlined three approaches, giving a brief descriptive summary of real professional practices in real educational programmes for incarcerated youngsters and exploring the ideological structures that support professional work.

Our aim in analysing and reporting our work in this way is to provide a detailed illustration of how Goldson's (2000) seminal theoretical distinction between 'young offenders' and 'children in need' can be 
identified at the deepest levels of professional practice and as a direct influence on day-to-day work in custodial and community settings. By proposing a formal typology of social educational interventions we aim to make a concrete contribution to the understanding of juvenile justice through the methods of national and international comparison.

How to conceptualise, organise and deliver education to young offenders as part of an overall strategy for sustainable social cohesion is a conundrum as the heart of contemporary approaches to youth justice. Our typology of educational practice in Spain is a contribution to the development of theory in this area, and one that we hope will be of practical use as a new generation of institutions and interventions emerges in Europe and beyond.

\section{REFERENCES}

Ahbel-Rappe, S and Kamtekar, R (2006) A Companion to Socrates (Blackwell Companions to Philosophy), Oxford, Blackwells.

Barzun J (2001) Del amanecer a la decadencia. Quinientos años de vida cultural en Occidente (de 1500 en adelante), Madrid, Taurus.

Beck U (1992) The Risk Society - Towards a New Modernity. Sage. London

Carabaña, J (2005) “¿Una educación sin autoridad ni sanción?”, Revista de Libros, ํㅡ 102, 19-23.

Cea d'Ancona, M. A. (1992): La justicia de menores en España, Madrid, CIS.

Costa, P (1996) Tribus urbanas: el ansia de identidad juvenil: entre el culto a la imagen y la autoafirmación a través de la violencia. Barcelona: Paidós Ibérica.

Centre for Social Justice (2013), Can Secure Colleges Transform Youth Custody? Centre for Social Justice, London. www.centreforsocialjustice.org.uk

Defensor del Pueblo (2009), Centros de Protección con Menores con trastornos de conducta y en situación de dificultad social, Madrid, 2009.

Foucault, Michel (1975) Discipline and Punish: the Birth of the Prison, New York: Random House

Gies D (1999) Modern Spanish Culture. Cambrige: Cambridge University Press http://dx.doi.org/10.1017/CCOL0521574080

Goldson B. (1999) Youth justice: contemporary policy and practice. Aldershot: Ashgate.

Goldson B (2000) 'CChildren in need' or 'young offenders'? Hardening ideology, organizational change and new challenges for social work with children in trouble", Child and Family Social Work, no 5, pp. 255-265.

http://dx.doi.org/10.1046/j.1365-2206.2000.00161.x

Hooper J, (1995) The New Spaniards. London: Penguin

Lechner, N. (1990): Los patios interiores de la democracia. Subjetividad y política, Santiago de Chile, FCE.

Ley del Menor (2000) (Ley Orgánica 5/2000), Madrid, Boletín Oficial del Estado 13/1/2000

Liebel, M. (2007): Entre protección y emancipación. Derecho de la infancia y políticas sociales, Universidad Complutense/ Facultad de Ciencias Políticas y Sociología.

Local Government Association (2013) LGA response to Transforming Youth Custody Ministry of Justice consultation. London, LGA. http://www.local.gov.uk/

Miguel A de (1990) Los Españoles: Sociología de la Vida Cotidiana. Madrid: Temas de hoy.

Millás, J. J. (2009): "Pablo Motos, la hormiga obrera. El éxito mediático de un niño hiperactivo", El País Semanal (7 de junio).

Ministry of Justice (2013): Transforming Youth Custody - Putting education at the heart of detention; Consultation Paper CP4/2013, H.M. Government, Ministry of Justice, London

Moreno, R. (2006): Panfleto antipedagógico, Barcelona, Lector universal

Morente, F. (1997): Los Menores Vulnerables. Jaén, Servicio de Publicaciones, Universidad de Jaén.

Morente, F. (Dir.) (2009): El laberinto social de la delincuencia Jóvenes adolescentes en la encrucijada. Madrid, Dyckinson.

Morente, F. y M. Domínguez (2009): Menores infractores en centros de reforma. Una mirada desde dentro. Reis, Núm. 126: 71106.

Muncie J (2008) The Punitive Turn in Juvenile Justice: Cultures of Control and Rights Compliance in Western Europe and the USA. Youth Justice Vol 8(2): 107 - 121 http://dx.doi.org/10.1177/1473225408091372

Newburn T and Shiner M (2006) Young People, Mentoring and Social Inclusion Youth Justice Vol 6(1): 23 - 41. http://dx.doi.org/10.1177/1473225406063450

O'Donoghue (2013) Clinks response to Ministry of Justice consultation

Transforming Youth Custody: Putting education at the heart of detention. London, Clinks. https://www.artsalliance.org.uk/ sites/default/files/Clinks response_TransformingYouth\%20C ustody_consultation.pdf

Pérez Jiménez, F. (2005): Menores infractores. Estudio empírico de la respuesta penal, Valencia, Tirant lo blanch.

Ricoeur, P. (2001): Ideología y utopía, Barcelona, Gedisa.

Ross C (2002) Contemporary Spain: A Handbook. London: Arnold

Savater F (2003) Los caminos para la libertad: ética y educación. F.C.E. de España, Madrid.

Young, J., (1994). The Exclusive Society: Social Exclusion, Crime and Difference in Late Modernity. London; Thousand Oaks: Sage Publications

Received on 19-08-2013

Accepted on 23-09-2013

Published on 28-10-2013

\section{DOI: http://dx.doi.org/10.6000/1929-4409.2013.02.40}

(C) 2013 Mejías et al.; Licensee Lifescience Global.

This is an open access article licensed under the terms of the Creative Commons Attribution Non-Commercial License (http://creativecommons.org/licenses/by-nc/3.0/) which permits unrestricted, non-commercial use, distribution and reproduction in any medium, provided the work is properly cited. 